ISSN 2076-0787

www.mdpi.com/journal/humanities

Article

\title{
The Meaning of Visual Thinking Strategies for Nursing Students
}

\section{Margaret Moorman}

Department of Community and Health Systems, School of Nursing, Indiana University, 1111 Middle Drive NU W415, Indianapolis, IN 46202, USA; E-Mail: mmmoorma@iu.edu; Tel.: +1-317-274-4352

Academic Editors: Sara Horton-Deutsch and Pamela Ironside

Received: 14 July 2015 / Accepted: 22 October 2015 / Published: 30 October 2015

\begin{abstract}
Nurse educators are called upon to provide innovative experiences for students to prepare them to work in complex healthcare settings. As part of this preparation, developing observational and communication skills is critical for nurses and can directly affect patient outcomes. Visual thinking strategies (VTS) is a teaching method that has been studied in primary education to develop communication and observational skills. VTS has potential to improve these same skills in nursing yet only one study has been done including nursing students and none have researched what meaning VTS has for them. This research study sought to answer the following questions: What meaning does VTS have for nursing students? How do nursing students use it in caring for patients? Students at a large Midwestern university in a Bachelor of Science program were recruited for participation. Students who voluntarily participated in a previous VTS experience were invited to participate in a second one, followed by an interview. Interpretive phenomenology was used to analyze the interviews and the following themes were identified: Feeling safe in learning and seeing and thinking differently. A literature review was performed to further expand these themes. Analysis of the findings and implications for future research are discussed.
\end{abstract}

Keywords: visual thinking strategies; art; nursing education; communication skills; thinking; observational skills

\section{Introduction}

Observational skills and the ability to pay close attention to detail are fundamental nursing skills that can improve patient outcomes. Equally important is the ability to accurately and effectively communicate 
these findings to other members of the healthcare team. These skills are not always intuitive and students often lack opportunities for practice. At the same time, nurse educators are called upon to provide innovative teaching strategies that are student-centered [1]. Visual Thinking Strategies (VTS) is a teaching technique that uses art to engage students through discussion to increase observational and communication skills [2]. This study sought to understand what meaning VTS had for nursing students and how they used it in caring for patients.

Art can be used to develop observational skills in students and can provide an innovative mechanism for students to develop higher levels of awareness and sensitivity to change [3]. Art has been used to improve observational skills in a variety ways in nursing education [4-19]. For instance, Frie et al. [5] found when nursing students viewed and described artwork at different distances, the students developed a broadened understanding of the role of perception and an awareness of the need to make accurate, precise observations. In a master's degree accelerated program, Pellico et al. [14] found students exposed to an art-based intervention generated more alternative diagnoses for patients in photographs. Art was used by Inskeep and Lisko, [6] in a fundamentals nursing course and found it helped students refine their ability to formulate nursing diagnoses and developed their critical thinking skills.

\subsection{Purpose of Study}

While the literature suggests art can be a powerful tool in nursing education and VTS holds promise as a teaching strategy in healthcare education, there is a gap in the literature regarding how nursing students perceive VTS and its value in their education. The purpose of this phenomenological study was to understand the meaning that VTS held for nursing students and to understand how students used VTS in their patient care. To understand the meaning of VTS may provide insight into educational practices for nurse educators. The following questions guided this study: What meaning does VTS have for students? and How do students use VTS in their care of patients?

\subsection{Visual Thinking Strategies}

Visual Thinking Strategies uses a trained facilitator to engage small groups of students with works of art $[2,20]$. VTS is grounded in the educational philosophies of theorist, Lev Vygotsky [21]. Vygotsky believed that learning is a socially mediated process in which verbalization of thoughts helps both educators and students reach higher levels of cognition [22]. As a constructivist, Vygotsky believed that knowledge is built on the interaction between the learner and others through the process of scaffolding. Scaffolding refers to a teaching method in which the instructor gradually releases responsibility to learners who gradually become more responsible for their own learning. Learners can scaffold off of other learners' ideas as they think out loud. The process of scaffolding helps learners construct meaning based on a framework. Then instructors may slowly withdraw support based on student needs as they progress in higher order thinking [23]. In the VTS process, the facilitator introduces questions, and learners are found to scaffold off of each other's comments during the process.

VTS facilitators are trained by the Visual Understanding in Education (VUE) organization [24]. In a typical VTS session, participants meet at an art museum and discuss three pre-selected works of art (chosen by the facilitator.) At the beginning of the session, participants gather around a painting and take a moment to look at it closely. After the initial view, the facilitator asks three standard questions, pausing 
after each question. The first question posed is: What is going on in this picture? After the participant gives a response, the facilitator asks: What do you see that makes you say that? Then the facilitator paraphrases what the participant says and then asks the group: What more can you find? [2,12,20,24].

Implicit in the teaching strategy is that after each student response, the facilitator asks, "What do you see that makes you say that?" After the each response, the facilitator paraphrases what was said and clarifies that the student was heard accurately. The ensuing discussion allows students to consider each other's interpretations while scaffolding off each other's comments, building a rich discussion about the art $[2,20]$.

Visual Thinking Strategies holds potential for teaching observational skills to healthcare providers [3,24-26]. After several exposures to a modified version of VTS in combination with an art appreciation class, Reilly et al. [3] found that hearing different perspectives enhanced group dynamics in a group of medical residents. In a randomized controlled study, Naghshineh et al. [26] used a modified version of VTS to enhance diagnostic acumen and visual literacy skills with medical and dental students. Results revealed that the intervention group scored higher on the visual skills examination than the control group.

In what appears to be the only study to date that has included nursing students, Klugman, Peel, and Beckmann-Mendez [25] examined the use of VTS with medical and nursing students at a large medical center. The researchers found that after three sessions of VTS, students spent more time looking at images, used more words to describe the images, and developed an improved tolerance for ambiguity.

\subsection{Method}

This study was done to explore the meaning of VTS for students and how they use it in caring for patients. Interpretive phenomenology is a research method that seeks to understand a particular phenomenon and allows for sensitive awareness of humans and how they react in their world [27]. Interpretive phenomenology was used for data analysis and, Institutional Review Board (IRB) was obtained from the author's university.

Forty-seven students were recruited from a group of 7th semester Bachelor of Science in Nursing (BSN) students who had participated in an optional VTS experience during a 6th semester obstetrical course at a large Midwestern University. Study invitations were sent via university email. The email explained that a study would be conducted that involved attending a second VST session and participating in an in depth interview following the experience. Twenty-eight students responded that they would be interested, but most of them had conflicts with the times and dates of the VTS sessions. Ten students agreed to participate, but two students declined immediately before the VTS session due to unspecified circumstances, leaving 8 students $(N=8)$. As an incentive for participation, students were offered a free membership to the local art museum. The final sample consisted of eight students.

The second VTS session was held at a local art museum and was led by a trained VTS facilitator. Three pieces of art were discussed using the standard VTS process during the one-hour session. The researcher conducted audio-recorded, individual face-to-face interviews with each student 1 to 2 weeks after the second VTS session. Each interview lasted approximately 1 hour and participants all chose to be interviewed on campus in a conference room, although the researcher offered to meet them at a place of their choosing. Guiding questions for the interview were "Tell me what meaning VTS had for you" 
and "Tell me how you have used VTS in nursing." Pictures of art pieces used in both VTS sessions were used during the interview to help facilitate discussion and remind participants what artwork they had viewed during their VTS session. The researcher also took observational notes during each interview.

Recordings were filed under pseudonyms to protect anonymity of participants. Of the eight participants, two were male, and six were female. One male participant was an accelerated student who had a previous degree, and the others were in the traditional 4-year BSN program. Because this interpretive phenomenological study explored the meaning of participants' experiences, demographic data other than gender and program type were not collected, as it was not intended to be generalizable.

A three-member research team analyzed the data. Two experts in interpretive phenomenology served as research mentors for the primary researcher. In interpretive phenomenology, the approach researchers take and their preconceptions cannot be separated from interpretations or writings, so keeping a journal is recommended [28,29]. Accordingly, observational notes, the investigator's journal, and interview transcriptions were used in thematic analysis $[27,28]$. The primary researcher identified initial themes, which were refined through debate, brainstorming, and discussion with the research mentors. Salient excerpts that characterize specific meanings were identified across transcripts from various participants. Paradigm cases that engaged the reader in the interpretation and offer an account that illuminates the interpretation were identified [28]. Trustworthiness of the analysis was achieved through the use of direct quotes, research teams, and returning to the transcripts to clarify meaning [13,27,28]. A literature review was also completed at the end of the study and is presented in the findings, as interpretive phenomenology asks the researcher to delve into the literature to discern and engage with what is already known about findings [30].

\section{Results and Discussion}

The research team identified two themes from the VTS experience: Feeling Safe in Learning, and Seeing and Thinking Differently. A third theme related to the characteristics of the facilitator emerged, but this theme did not relate to the participants' experience and is considered beyond the scope of this manuscript.

\subsection{Feeling Safe in Learning}

During interviews, participants described specifically the role of the facilitator and how she responded to their participation during the VTS sessions. When a student answered a question, she listened intently, paraphrased back what was said, and sought clarification. The facilitator did not give any one comment more attention, nor did she indicate that any answer was right or wrong. All comments received equal attention. Participants compared this to their experiences in the classroom and expressed that often classroom interactions stifled learning. Examples of how instructors scrutinized answers and labeled answers as "right" or "wrong" left them feeling ashamed or embarrassed and less likely to participate in the future. The research team identified the theme "Feeling Safe in Learning" after reviewing and discussing participant transcripts and interpretations.

Participants identified the role of the facilitator in VTS as a key component of feeling safe. She listened attentively while each person spoke and sought to understand and clarify each statement. "She had to really listen carefully to what each person said. She was so attentive and engaged with us! It was 
the first time I've really felt listened to in nursing school." Another participant noticed that the facilitator was very respectful, waited until each person spoke, and then validated what was said. Because of her gentle approach, participants found they were more likely to respond, because of the way the facilitator showed no partiality or favor toward any one response. All responses were given equal attention. "If each response is given equal attention, I am more willing to go out on a limb and try to discover more meanings because she is open to it. If I felt she was just looking for one answer, I wouldn't be as open." Identified by participants as "being more open", the facilitator encouraged them to push their thinking in a way that felt safe and validated. Participants noted this in contrast to classroom responses, when they often felt shamed if they gave a wrong response.

The facilitator invited participation by asking the question "What is going on in this work of art?" As she listened and paraphrased back what was said, participants felt respected for their feedback in the facilitator's "presence". "She couldn't be thinking about what she had to do, because she was really listening to me. I didn't feel like I had to participate, but wanted to because she was so encouraging". This sense of presence and respect was important to students' feeling of being in a safe learning environment.

Another component associated with feeling safe in learning was that they were able to express themselves freely, without judgment or criticism. They were encouraged to explore meaning and ideas by the VTS facilitator. One participant noticed that the VTS facilitator validated his initial impressions by paraphrasing back and seeking understanding. He said "She reflects what you say. So it kind of gives substance to what you're saying. It's recognition that what you're saying is not necessarily right, but it's an acknowledgment of what you said." He noted that she guided the discussions about art without giving any one response more attention than any other. He appreciated being able to hear how others were thinking out loud and this pushed his thinking to expand while he considered other interpretations, at the same time, holding his own.

He went further by saying "Everyone has an equal voice...I think it puts everyone on an equal plane, to fully communicate your opinion and that's validated by the facilitator." Another participant noted "she is very open and friendly." Because there was no right or wrong, she found that she was able to "explore and think differently" about the artwork. Yet another participant found the line of questioning by the facilitator was the same for each work of art, and that provided a systematic way for her to participate and get involved with the discussions. By using the same line of questioning, participants could anticipate what their answer would be and felt safe to share in the group discussion.

Other students explained that being in the art museum instead of the hospital or a classroom made them feel safe. Students found the art museum to be neutral territory, where there were no lab coats, no scrubs, no nametags, and everyone was treated with respect and given equal attention. They found the art museum relaxing, comfortable and welcoming. They voiced that they were more likely to participate in the art museum than in the classroom, and the very place VTS was held made it more conducive to their participation.

Some students felt that even asking questions to their nurses in the clinical setting might jeopardize their opportunities to get better clinical experiences and was risky. This stifled their probing questions and inquiries in clinical practice. However, with VTS, they were encouraged to participate and give their opinions, which they perceived as augmenting their learning in a safe way. They also believed that the facilitator was genuinely interested in their answers, so they contributed more to the conversations about art than they would have in a clinical situation. 
The VTS experience was not graded, and participants said this made it more likely that they would participate. "VTS felt open and free to me. I was able to express my thoughts and opinions about artwork in a way that felt much safer than how we participate in class. The facilitator was really open and affirming, and I was much more likely to share in that environment than in the classroom."

\subsection{Thinking and Seeing Differently}

After experiencing VTS in two separate sessions, students noticed that they were able to assess their patients more critically and noticed more nuances and detail. They also discussed that they were more precise in providing details to nurses, physicians, and other members of the healthcare team after the VTS experience when they went into the clinical setting. One student explained:

"In clinical, you get report about your patient, kind of like the whole picture. Then you go into the patient room and you start to see the patient and the all of the other factors like the medical equipment, medicines, culture, history, family and all of the little details. All of those little things together kind of make up the big picture like a work of art. You get a sense of the big picture, and then you go in for more details and data. You see it differently after getting the smaller pieces and it validates the big picture" [11].

Other students found that they gave more detail in their charting or reports to other nurses, stating facts to back up their observations.

"I didn't just chart that she had swelling in her legs...I gave evidence to back it up. Her socks were tight and she had imprints and pitting edema. She also had no swelling the day before, so I compared and contrasted as I gave report to the resident. I was much more thorough about the swelling than before I experienced VTS" [11].

One student likened his experiences with VTS to walking into a critical care unit for the first time:

"You first walk in and it's too much and it's so overwhelming. But then you break it down into little pieces and it's like that large work of art from Africa we looked at. It was way too busy when I first saw it. I didn't like it and wanted to walk away. But, after we started talking about it and everyone was noticing small details, we were able to find a common meaning for the larger work of art and its meaning. We broke it down into little pieces, and it makes the big picture seem not so scary. That is what I ended up doing in the ICU the first day. I was overwhelmed, but then I just went to look at the medicines, then the vent, then the drains...I broke it down into small pieces, and it helped me to get a better understanding of the big picture!" [11].

The ability to formulate and reformulate an experience from the classroom to clinical is rare and distinctive, and, according to Vygotsky, enhances learning [21]. Students looked at the artwork, discussed it, then reported looking again, and looking deeper for meaning. Discussions that occurred around the work of art encouraged participation and scaffolding off of others' comments, which enhanced participants' ability to find more and explore more about the work of art. 


\section{Conclusions}

Two major themes emerged from interviews of students who experienced VTS: "feeling safe" in a learning environment and "seeing and thinking differently." The interviews revealed that previous to VTS, the students did not feel they had a voice in their nursing education experiences. Shame and fear of being wrong were roadblocks to feeling safe to explore and in their ability to learn, but VTS offered them the opportunity to speak out without judgment or fear of consequences.

Fear of speaking up in nursing education has been documented by other researchers. In a study of first-year nursing students from the United Kingdom, Bradbury-Jones, Sambrook, and Irvine's [31] found students kept quiet in several clinical situations even when they felt a patient's health might be compromised primarily because they feared ramifications from supervising nurses. While the students recognized that asking questions was inherent in their role as a student, learning to ask questions in difficult situations took time [31]. In another study of nursing students from Australia and the United Kingdom, Levett-Jones and Lathlean [32] found the hierarchical structure of healthcare induced a feeling of being inferior for nursing students. Their research highlighted how nursing students conform when they are in a clinical situation and adopt the institution's values and norms rather than challenge them as a way to be accepted by nursing staff.

In the current study, students' responses during the interviews revealed concerns that questioning their nurse in the clinical setting might result in being denied clinical experiences. Therefore, students often conformed to their perceived role as silent observer. Conformity is a way for students to feel safe [33-35]. Yet, patient safety is compromised when nursing students do not feel safe to speak out. The characteristic of being quiet and acquiescing is inconsistent with developing independent thinkers who practice to the fullest extent of their education as set forth by the Institute of Medicine in 2010. Failing to act can lead to undesirable patient outcomes [36]. Because nurses are the patient's first line of defense, they are responsible for advocating for the patient through clarification, verbal interruption, and communications.

Nurse educators need to find better strategies to help students learn to speak out so that patient outcomes are improved and student learning is augmented [16]. The findings of the current study suggest that VTS holds potential as a technique to improve observational and communication skills, teaching students to speak out in safe ways, which may help mitigate errors in patient care.

A safe learning environment encompasses connections among students and instructors, elimination of power-based relationships, and mutual listening and empathy [37]. VTS also employs techniques to promote students' and instructors' connection through art in a safe learning environment. Participants in this current study appreciated being heard and feeling free to speak out without judgment or criticism. In fact, participants identified how the role of the facilitator often made them more likely to participate. By having their findings validated and paraphrased back, participants were likely to offer further insights as conversations continued. They participated with each consecutive discussion about a work of art, identifying the actions of the facilitator as encouraging and supportive.

This finding of feeling safe in learning reveals a deeper sense of safety for students outside of the classroom. Participants felt connected and cared for by the facilitator. Nell Nodding identified four components of a caring curriculum: modeling, practice, authentic dialogue, and confirmation/affirmation [38]. These components were also identified by students through the role of 
the VTS facilitator. Participants found that she actively listened to them, paraphrased what was said, sought further understanding for clarification, and affirmed their contributions to the group. These components offer nurse educators opportunities to provide similar experiences for students in the classroom.

This interaction between the facilitator and student fosters a social interaction that is a key component in the educational philosophies of learning in a social context as espoused by Vygotsky [21]. Learning based on social interactions shifts away from teacher-centered modes of learning that emphasizes content to a focus on student-centered learning $[1,33,34]$. The VTS facilitator models presence, active listening, and mutual respect as she interacts with participants. This nourishes a student's willingness to participate and may potentially influence how they listen to their patients.

Thinking and seeing differently as a theme reinforces the findings of previous research studies on VTS in health profession education. Klugman et al. [25] found the use of VTS increased descriptive words, tolerance of ambiguity, and willingness to communicate. In Klugman et al.'s study, students spent more time looking at art after the VTS intervention. Time spent looking at artwork and the number of words used to describe the work were both representative measures of observation. Klugman et al. projected that these outcomes could translate to an increase in the likelihood that students would spend more time interacting with patients and suggested the lack of hierarchy in the art museum may promote participation.

As participants found the art museum to be a safe place to learn and discuss, the art work itself serves to encourage participation. Art, like illness, can be ambiguous, rarely presenting right or wrong. Students were never told the rightness of their responses; they were simply encouraged to say more. Through art, students developed significantly increased comfort with ambiguity. Ambiguity can be difficult for nursing students, who are often taught there is only one right answer. VTS questioning also lends itself to providing a safe, predictable line of questioning that students can use in a clinical setting. They can model the active listening and paraphrasing that the VTS facilitator demonstrated during the session in caring for their patients. This, in turn may augment a safe way for patients to discuss and communicate their feeling about illness and hospitalization.

Students who experienced VTS felt their ability to see and think was enhanced by looking at art and being asked to give visual evidence for what they saw. These findings are similar to those of Naghshineh et al. [26] who found a modified VTS course increased medical and dental students' ability to describe physical findings. Pellico et al. [14] also found nursing students who participated in an art experience were able to give more objective descriptions of photographs and offered more alternative diagnoses.

Asked how VTS applied to their work as future nurses, participants in this study felt that going from the big picture to noticing detail, and then back to the big picture was a metaphor for how they viewed critically ill patients and those with multiple medical conditions. They also found that considering others' opinions expanded their thinking. Narrative pedagogy has been described in nursing education as one teaching strategy to increase students' abilities to challenge assumptions and interpret clinical findings, and think differently $[39,40]$. Similarly VTS helps students uncover meanings and serves as a path to help students discover their voice as they seek to find meaning in a work of art. 


\section{Limitations of Study and Implications}

This was a qualitative study designed to identify themes for future research. It was not designed to establish a causal relationship. Participants in this study experienced two, one-hour VTS sessions. A series of several VTS experiences might have provided more of a structure and practice for participants, which could have yielded more uses for it in their clinical practices. Previous VTS studies have utilized either three sessions or a full semester of VTS experiences, although no proscribed number has been determined to be optimal [2]. However, the findings provide implications for teaching nursing students.

This VTS learning experience revealed vulnerabilities in student learning experiences and helped to uncover and reveal ways in which students felt safe to explore and expand their learning. The VTS experience with art also uncovered an avenue for students to think and see differently through careful consideration of others' thinking and seeing. This study revealed the need for students to feel safe in exploring and questioning ideas and practice. Results also indicated that VTS helps students to think and see differently. The social context gave students the opportunity to consider multiple interpretations of what a work of art means and that no single interpretation stood out as valid or correct. In other words, students were able to consider safely all the possibilities and explore several potential meanings for a work of art. The VTS experience has the potential to influence nursing so that nursing students can learn to consider others' points of view as they work in healthcare teams caring for patients.

VTS exposes students to the arts in a unique way. Art can expand thinking and provide insight into the human experience for students. The arts can foster perspective and help students learn to connect with others in a meaningful way. VTS exposes students to the arts, and also provides students an opportunity to connect with each other and learn to have an authentic presence. Futures studies should explore how students learn to connect with their own emotions and articulate these in meaningful ways with others.

Future studies could specifically look at the role of the facilitator in VTS and how those interactions with participants enhance the experience. There is also a need to expand the study of VTS in interprofessional education with the inclusion of medical students, physical therapists, social workers, and nurses. The exploration of how healthcare teams interact and find meaning in VTS experiences would provide insight into this innovative teaching strategy. Furthermore, VTS and the use of the questions used in this method of teaching has the potential to expand healthcare workers' understanding about how various members approach healthcare through thinking aloud and working in a safe, neutral environment of the art museum. Finally, VTS experiences would provide a vehicle for healthcare members to understand each other's roles and hear how others think, providing more insight into other healthcare provider's roles and responsibilities.

\section{Acknowledgments}

The author was a participant in the 2015 NLN Scholarly Writing Retreat, sponsored by the NLN Chamberlain College of Nursing Center for the Advancement of the Science of Nursing Education. The author would also like to thank Lori Candela for chairing her committee, as well as Sherry Sims and Pam Ironside for being research mentors for this study. 


\section{Conflicts of Interest}

The author declares no conflict of interest.

\section{References}

1. Patricia Benner, Molly Sutphen, Victoria Leonard, and Lisa Day. Educating Nurses: A Call for Radical Transformation. Hoboken: John Wiley \& Sons, 2009, vol. 15.

2. Abigail Housen. Eye of the Beholder: Research, Theory and Practice. Lisbon: Visual Understanding in Education, 2005.

3. Jo Marie Reilly, Jeffrey Ring, and Linda Duke. "Visual thinking strategies: A new role for art in medical education." Family Medicine 37 (2005): 250-2.

4. Jacqueline C. Dolev, Linda Krohner Friedlaender, and Irwin M. Braverman. "Use of fine art to enhance visual diagnostic skills." Jama 286 (2001): 1020-21.

5. Judith Frei, Sarah E. Alvarez, and Michelle B. Alexander. "Ways of seeing: using the visual arts in nursing education.” Journal of Nursing Education 49 (2010): 672-76.

6. Sandra J. Inskeep, and Susan A. Lisko. "Alternative clinical nursing experience in an art gallery." Nurse Educator 26 (2001): 117-19.

7. Sona K. Jasani, and Norma S. Saks. "Utilizing visual art to enhance the clinical observation skills of medical students." Medical Teacher 35 (2013): e1327-31.

8. Alice Jensen, and Mary Curtis. "A descriptive qualitative study of student learning in a psychosocial nursing class infused with art, literature, music, and film." International Journal of Nursing Education Scholarship 5 (2008): 1-9.

9. Craig M. Klugman, and Diana Beckmann-Mendez. "One thousand words: Evaluating an interdisciplinary art education program." The Journal of Nursing Education 54 (2015): 220-23.

10. Andrew McKie, Violet Adams, John P. Gass, and Colin Macduff. "Windows and mirrors: Reflections of a module team teaching the arts in nurse education." Nurse Education in Practice 8 (2008): 156-64.

11. Margaret Moorman. "The Meaning of Visual Thinking Strategies for Nursing Students." Ph.D. dissertation, University of Nevada, 1 August 2013.

12. Margaret Moorman, and Desiree Hensel. "Using Visual Thinking Strategies in Nursing Education." Nurse Educator Published electronically 10 June 2015. doi: 10.1097/NNE.0000000000000185.

13. Richard E. Palmer. Hermeneutics: Interpretation Theory in Schleiermacher, Dilthey, Heidegger, and Gadamer. Chicago: Northwestern University Press, 1969.

14. Linda Honan Pellico, Linda Friedlaender, and Kristopher P. Fennie. "Looking is not seeing: Using art to improve observational skills." Journal of Nursing Education 48 (2009): 648-53.

15. Anastasia P. Samaras. "Explorations in using arts-based self-study methods." International Journal of Qualitative Studies in Education 23 (2010): 719-36.

16. Alison Steven, Carin Magnusson, Pam Smith, and Pauline H. Pearson. "Patient safety in nursing education: Contexts, tensions and feeling safe to learn." Nurse Education Today 34 (2014): 277-84.

17. Brenda L. Whitman, and Wanda J. Rose. "Using art to express a personal philosophy of nursing." Nurse Educator 28 (2003): 166-69. 
18. Brit Wikstrom. "Nursing education at an art gallery." Journal of Nursing Scholarship 32 (2000): 197-99.

19. Brit Wikstrom. "Works of art: A complement to theoretical knowledge when teaching nursing care." Journal of Clinical Nursing 10 (2001): 25-32.

20. Abigail C. Housen. "Aesthetic thought, critical thinking and transfer." Arts and Learning Research 18 (2002): 2001-2.

21. Lev S. Vygotsky. Mind in Society: The Development of Higher Psychological Processes. Cambridge: Harvard University Press, 1978.

22. Debra Sanders, and Dorette Sugg Welk. "Strategies to scaffold student learning: Applying Vygotsky's zone of proximal development." Nurse Educator 30 (2005): 203-7.

23. Carol Rodgers. "Voices inside schools." Harvard Educational Review 72 (2002): 230-54.

24. Alexa Miller, Michelle Grohe, Shahram Khoshbin, and Joel T. Katz. "From the galleries to the clinic: Applying art museum lessons to patient care." Journal of Medical Humanities 34 (2013): 433-38.

25. Craig M. Klugman, Jennifer Peel, and Diana Beckmann-Mendez. "Art rounds: Teaching interprofessional students visual thinking strategies at one school." Academic Medicine 86 (2011): 1266-71.

26. Sheila Naghshineh, Janet P. Hafler, Alexa R. Miller, Maria A. Blanco, Stuart R. Lipsitz, Rachel P. Dubroff, Shahram Khoshbin, and Joel T. Katz. "Formal art observation training improves medical students' visual diagnostic skills.” Journal of General Internal Medicine 23 (2008): 991-97.

27. Janice D. Crist, and Christine A. Tanner. "Interpretation/analysis methods in hermeneutic interpretive phenomenology." Nursing Research 52 (2003): 202-5.

28. Patricia Benner, ed. Interpretive Phenomenology: Embodiment, Caring, and Ethics in Health and Illness. Thousand Oaks: Sage publications, 1994.

29. Lesley Lowes, and Morag A. Prowse. "Standing outside the interview process? The illusion of objectivity in phenomenological data generation." International Journal of Nursing Studies 38 (2001): 471-80.

30. Elizabeth Ann Smythe, and Deborah Gail Spence. "Re-viewing literature in hermeneutic research." International Journal of Qualitative Methods 11 (2012): 12-25.

31. Caroline Bradbury-Jones, Sally Sambrook, and Fiona Irvine. "Nursing students and the issue of voice: A qualitative study." Nurse Education Today 31 (2011): 628-32.

32. Tracy Levett-Jones, and Judith Lathlean. "'Don't rock the boat': Nursing students' experiences of conformity and compliance." Nurse Education Today 29 (2009): 342-49.

33. Patricia E. Benner. From Novice to Expert: Excellence and Power in Clinical Nursing Practice. San Francisco: Pearson, 2001.

34. Liz Berragan. "Simulation: An Effective Pedagogical Approach for Nursing?" Nurse Education Today 31 (2011): 660-63.

35. Carol A. Nolan. "Learning on clinical placement: The experience of six Australian student nurses." Nurse Education Today 18 (1998): 622-29.

36. Gregory A. DeBourgh, and Susan K. Prion. "Patient safety manifesto: A professional imperative for prelicensure nursing education." Journal of Professional Nursing 28 (2012): 110-18. 
37. Mary Ellen Bond. "Exposing shame and its effect on clinical nursing education." Journal of Nursing Education 48 (2009): 132-40.

38. Gwen Sherwood, and Sara Horton-Deutsch. Reflective Organizations: On the Front Lines of QSEN \& Reflective Practice Implementation. Indianapolis: Sigma Theta Tau International, 2015.

39. Pamela M. Ironside. "Using narrative pedagogy: Learning and practicing interpretive thinking." Journal of Advanced Nursing 55 (2006): 478-86.

40. Martha M. Scheckel, and Pamela M. Ironside. "Cultivating interpretive thinking through enacting narrative pedagogy.” Nursing Outlook 54 (2006): 159-65.

(C) 2015 by the author; licensee MDPI, Basel, Switzerland. This article is an open access article distributed under the terms and conditions of the Creative Commons Attribution license (http://creativecommons.org/licenses/by/4.0/). 